\title{
Dysregulation of Cell Adhesion Proteins and Cardiac Arrhythmogenesis
}

\author{
Jifen Li, MD, PhD; Vickas V. Patel MD, PhD and Glenn L. Radice, PhD
}

\begin{abstract}
Proper mechanical and electrical coupling of cardiomyocytes is crucial for normal propagation of the electrical impulse throughout the working myocardium. Various proteins on the surface of cardiomyocytes are responsible for the integration of structural information and cell-cell communication. Increasing evidence from diseased myocardium and animal models indicates that alteration in electrical coupling via gap junctions is a critical determinant in the development of an arrhythmogenic substrate. What is less clear is how gap junctions are maintained and regulated in the working myocardium. In this review, we present data from human disease and animal models that support the idea that cell adhesion proteins regulate the stability of the gap junction protein, connexin.
\end{abstract}

Keywords: Arrhythmia; Cadherin; Connexin; Gap junction; Intercalated disc

$\mathrm{T}$ he normal cardiac electrical cycle begins with diastolic depolarization of the cells within the sinoatrial (SA) node which generates an action potential and spreads to depolarize the surrounding atrial myocardium. The electrical impulse is then conducted through the atrioventricular (AV) node, down the His bundle to the bundle branches and distributed to the working myocardium of the ventricles through the Purkinje fiber network. For proper excitation-contraction coupling to occur, electrical conduction must be precisely timed with the corresponding mechanical contraction. Therefore, efficient cardiac contractile function is highly dependent upon the coordinated mechanical and electrical activation of the myocardial tissue. In this regard, it is of the utmost importance that the structural integrity of the myocardium is tightly maintained; this is largely achieved by the end-to-end connections between myocytes called intercalated discs. The intercalated disc consists of three main junctional complexes: adherens junctions, gap junctions and desmosomes. The adherens junction provides strong cell-cell adhesion, which is mediated by the cadherin/catenin complex via linkage to the actin cytoskeleton. The gap junction provides intercellular communication via small molecules and ions that pass through a channel generated by a family of proteins called connexins. The desmosome provides structural

Reprint Requests: Glenn L. Radice, PhD, Center for Research on Reproduction and Women's Health, University of Pennsylvania, I355 Biomedical Research Building II/III, 42I Curie Blvd., Philadelphia, PA 19104, Tel.: 2I5-898-0I64, Fax: 2I5-573-5408,Email: radice@mail.med.upenn.edu support through interactions of desmosomal cadherins with the intermediate filament system. The different junctional complexes must be properly organized within the intercalated disc to mediate normal mechanical and electrical coupling between the individual cardiomyocytes in the heart to preserve normal cardiac function.

Sudden cardiac death (SCD) is generally the result of an abrupt ventricular tachyarrhythmia that compromises cardiac output to the brain and other organs. SCD claims almost 450,000 lives per year in the United States, adding considerable economic and personal costs to our health care system. Despite tremendous advances in the effective treatment of SCD using internal cardioverter defibrillators (ICDs), the incidence of SCD continues to rise. The reasons for the rising incidence of SCD with widely available ICDs are the result of multiple factors. One of the leading contributors to the increasing incidence of SCD is our inability to clearly identify all high-risk patients who will benefit from ICDs and emphasizes the fact that we do not completely understand the mechanisms underlying SCD. In addition, ICDs are not without fault as they are relatively expensive and like any mechanical device are prone to failure. Patients who have received an ICD may have societal restrictions placed upon their ability to operate a motor

Grant Support: Postdoctoral fellowship from PA/DE Affiliate of American Heart Association (0425656U) (J.L.), KO8 award from NIH (HL074I 08) (V.P.). G.R. is an Established Investigator of the American Heart Association.

Received: October 12, 2005 Revised: December 14, 2005 Accepted: January 13, 2006 


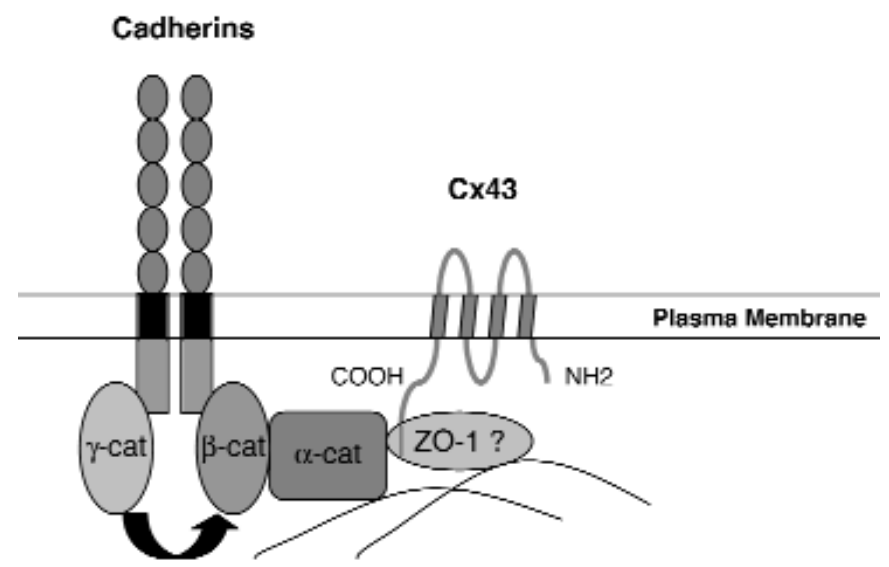

Figure 1. Schematic representation of how the cadherin/catenin complex may interact with the gap junction protein, Cx43. The cytoplasmic tail of cadherin interacts in a mutually exclusive manner with either $\beta$-catenin or $\gamma$-catenin (i.e., plakoglobin). $\beta$-catenin or $\gamma$-catenin link cadherins to $\alpha$-catenin and $\alpha$-catenin can bind to the actin cytoskeleton. ZO-1 or another cytoskeletal protein functions as a cross-linker between cadherin/catenin complex and $\mathrm{Cx} 43$, thus stabilizing gap junctions at the plasma membrane.

vehicle or obtain work in certain professions (e.g., welding). ICDs can also be a significant source of morbidity due to inappropriate therapy, post-implant infection and occasional need for lead/system revision. Therefore, a better understanding of the mechanisms contributing to SCD could lead to alternative therapies, which may reduce the need for ICD therapy and the associated costs. Aberrant cell-cell coupling through junctional complexes is observed in many of the major forms of human heart disease, as well as in experimental animal heart disease, which is associated with an increased risk of arrhythmias and SCD. ${ }^{1-5}$ However, the molecular mechanism underlying cellular uncoupling in the heart with the subsequent development of cardiac electrical disorders and arrhythmogenesis is still poorly understood.

In this review we describe how the adherens junction protein $\mathrm{N}$-cadherin regulates gap junction function in the working myocardium. In particular, we discuss recent findings that point to a central role for the N-cadherin/catenin complex in maintaining cardiac function and how perturbations of the normal interactions within this complex lead to disease.

\section{Cell-Cell Coupling Mediated by the Cell Adhesion Protein, N-Cadherin}

Most cells express multiple cadherin subtypes, for example, skeletal muscle expresses R-cadherin, M-cadherin and $\mathrm{N}$-cadherin. In contrast, cardiac muscle depends upon only one classical cadherin, N-cadherin. N-cadherin is highly expressed by the developing and mature myocardium, where it is found predominantly in the fascia adherens of the transverse region of intercalated disks and in regions of close lateral contact between neighboring myocytes. ${ }^{6} \mathrm{~N}$-cadherin is also found in extrajunctional sites where it co-localizes with $\alpha$-actinin in the peripheral Z-disks of the sarcomeres. ${ }^{7}$
Classic cadherins, including E-, P- and N-cadherin, constitute a family of cell surface glycoproteins that mediate calcium-dependent adhesion. ${ }^{8}$ The classical cadherins are single pass transmembrane proteins with five extracellular domains, a single transmembrane domain and one cytoplasmic domain. Through their homophilic binding and adhesive specificities, cadherins are thought to play a critical role in embryonic development and the maintenance of normal tissue architecture in the adult. A highly conserved cytoplasmic domain that associates with a family of cytoplasmic proteins called catenins, including $\alpha$-catenin, $\beta$-catenin, $\gamma$-catenin (also known as plakoglobin) and p120ctn, defines the classic cadherins. Formation of the cadherin-catenin complex is required for cadherin-mediated cell adhesion, and it is believed that $\alpha$-catenin, which binds to the cadherin- $\beta$-catenin or cadherin-plakoglobin complex, mediates linkage to the actin cytoskeleton (figure 1).

Initial attempts to understand the role of $\mathrm{N}$-cadherin in the heart using genetically engineered mice were limited due to the fact that $\mathrm{N}$-cadherin is required for embryonic development. Genetically engineered mice with a germline deletion of N-cadherin experience embryonic lethality shortly after implantation, accompanied by multiple embryonic abnormalities that include severe cardiovascular defects. ${ }^{9} \mathrm{On}$ the other hand, mice engineered to overexpress $\mathrm{N}$-cadherin or misexpress E-cadherin in the adult mouse myocardium suffer from a dilated cardiomyopathy due to cadherin-mediated modulation of intercalated disc function. ${ }^{10}$ We speculate that excess cadherin/catenin complexes compared with myofibrils may alter the contractile dynamics by changing the stoichiometry of the cadherin/myofibril connection leading to less efficient force transduction across the plasma membrane. ${ }^{10}$ Chimeric mouse embryos derived from $\mathrm{N}$-cadherin-deficient embryonic stem cells (genetically engineered mice where $\mathrm{N}$-cadherin is completely deleted from some of the cardiomyocytes but fully expressed in the others) demonstrate that $\mathrm{N}$-cadherin-null cardiomyocytes are excluded from the myocardium during development which emphasizes the importance of N-cadherin in myocardial cell-cell interactions. ${ }^{11}$ Recently, we were able to take advantage of a cardiac-specific, inducible $\mathrm{Cre}$ transgene which allowed us to specifically delete $\mathrm{N}$-cadherin in the adult myocardium after development was fully complete. ${ }^{12,13}$ Deletion of N-cadherin in these conditional knockout mice (N-cad CKO) resulted in loss of the intercalated disc structure (figure 2), including the adherens junctions and desmosomes. The mutant mice exhibited a modest dilated cardiomyopathy and impaired cardiac function, with most animals dying within 2 months after deletion of the N-cadherin gene. The animals exhibited no signs of heart failure prior to sudden death. In addition, decreased sarcomere length and increased Z-line thickness were observed in the mutant hearts by electron microscopy analysis (figure 2), which is consistent with loss of muscle tension because $\mathrm{N}$-cadherin was no longer available to anchor myofibrils at the plasma membrane. Quantitative analysis of cardiac-gated magnetic resonance images demonstrated 


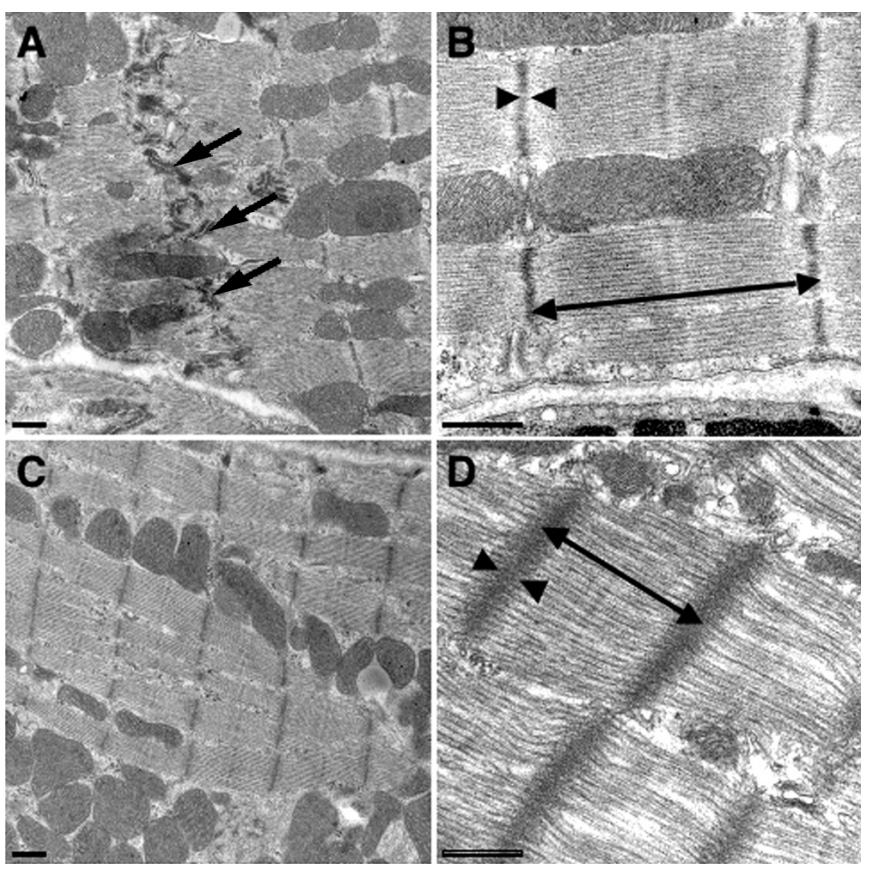

Figure 2. Transmission electron microscopy of $\mathrm{N}$-cadherin CKO hearts. Electron micrographs of ventricular myocardium from N-cadflox/-, Cre hearts minus tamoxifen $(\mathrm{A}, \mathrm{B})$ or 5 weeks following Tam administration (C, D). Intercalated discs (arrow) were readily visualized in the control (A). In contrast, these structures were absent in the $\mathrm{N}$-cad CKO heart $(C)$. The myofibrils appeared distorted in the mutant (D) compared to control (B) with increased sarcomere length (double headed arrow) and wider, less dense Z-lines (arrowheads). Bars, 500 $\mathrm{nm}$. Reprinted with permission from Kostetskii et al. Induced deletion of the $\mathrm{N}$-cadherin gene in the heart leads to dissolution of the intercalated disc structure. Circ Res 2005;96:346-354. Copyright 2005 Lippincott Williams \& Wilkins. All rights reserved.

significant reduction of left ventricular ejection fraction (approximately 25\%) and cardiac output (approximately 50\%) in the N-cad CKO mice compared with wild-type. This animal model provides the first demonstration of the hierarchical relationship of the structural components of the intercalated disc in the working myocardium, thus establishing the paramount importance of $\mathrm{N}$-cadherin in maintaining the structural integrity of the heart. ${ }^{12}$

\section{Altered Gap Junction Function in the Pathogenesis of Cardiac Arrhythmias}

Gap junctions are plaques of multiple intercellular channels that connect the cytoplasm of adjacent cells. An individual channel is created by stable, noncovalent interactions of two hemichannels, referred to as connexons. Each connexon is composed of six connexin proteins. A major role of gap junctions in the myocardium is to enable rapid and coordinated electrical excitation, a prerequisite for normal rhythmic cardiac function. In the mammalian heart, gap junction channels are mainly composed of three different types of connexin protein, $\mathrm{Cx} 43, \mathrm{Cx} 40$ and $\mathrm{Cx} 45$, whose expression is subject to spatio-temporal and species-specific regulation. $\mathrm{Cx} 43$ is the main constituent of cardiac gap junctions and in the rodent it is expressed in all atrial and ventricular myocytes. In the rodent heart $\mathrm{Cx} 40$ is expressed in atrial myocytes and in the AV conducting system, while $\mathrm{Cx} 45$ is expressed at significant levels only in the conductive system and the epicardial coronary arteries. The co-localization of different connexin proteins in gap junction plaques, observed immunohistochemically, probably reflects the formation of heterotypic or heteromeric gap junction channels. ${ }^{14-17}$ Cardiac myocytes actively regulate the level of coupling they have to neighboring cells by multiple mechanisms, which include alterations in connexin expression, regulation of trafficking and turnover, and modulation of channel properties. In the diseased heart, $\mathrm{Cx} 43$ is often down-regulated, redistributed and preferentially lost from the intercalated disc. ${ }^{18-20}$ Disturbances in the distribution of gap junctions and reduced levels of $\mathrm{Cx} 43$ occur not only in association with established infarct scar tissue in the human heart, but have been shown in experimental animals to be initiated rapidly after ventricular ischemia and infarction. 4,21,22 Alterations in connexin expression and spatial remodeling of gap junctions in regions bordering healing infarcts have been implicated in the development of slow, heterogeneous conduction and conduction block critical in reentrant arrhythmogenesis.22 More widespread spectacular disordered arrangements of ventricular $\mathrm{Cx} 43$ gap junctions are an inevitable consequence of the haphazard myocyte organization characteristic of human hypertrophic cardiomyopathy, the most common cause of SCD due to arrhythmia. $^{23}$

Recent studies using genetically engineered mouse models have demonstrated a link between defective connexins and cardiac arrhythmias (table 1). Cx40 knockout mice exhibit atrial electrical abnormalities, as well as central conduction system defects. ${ }^{24-26}$ Following atrial burst pacing, Cx40 knockout mice develop atrial tachycardia, suggesting that a loss of $\mathrm{Cx} 40$ can confer an increased susceptibility to atrial arrhythmias. ${ }^{26}$ Recently, a rare genotype has been identified for two $\mathrm{Cx} 40$ polymorphisms that have been linked to clinical atrial standstill. 27 Atrial standstill is an extremely rare arrhythmia, characterized by the absence of electrical and mechanical activity in the atria. Mice with cardiac-specific loss of $\mathrm{Cx} 43$ have preserved cardiac structure and contractile function, but they uniformly develop SCD from spontaneous ventricular arrhythmias. Analysis of the epicardial activation wavefronts using optical mapping techniques in these animals demonstrates decreased ventricular conduction velocity and increased anisotropic conduction in these mice. ${ }^{28}$ Mice engineered with a postnatal, cardiac-specific conditional deletion of $\mathrm{Cx} 43$ in their hearts manifest reduced conduction velocity and enhanced arrhythmogeneity. 29,30 These findings suggest that in the setting of a general, heterogeneous decrease in gap junction expression, the heart becomes more vulnerable to arrhythmogenesis. The increased propensity of arrhythmogenesis in the setting of decreased gap junction expression is probably due to the loss in conduction velocity and increase in anisotropy that contributes to unidirectional block and slowed conduction within functional and/or fixed 
Table 1. Cardiac intercalated disc protein defects linked to cardiac arrhythmia in human and animal models.

\begin{tabular}{|c|c|c|c|c|}
\hline Gene mutation & Species & Inheritance & Disease phenotype & Reference \\
\hline \multicolumn{5}{|l|}{ Defect in adherens junctions } \\
\hline $\mathrm{N}$-cadherin & Mouse & Cardiac-specific loss & $\begin{array}{l}\text { Spontaneous ventricular tachycardia, } \\
\text { slow conduction velocity, SCD, moderate } \\
\text { biventricular dilative cardiomyopathy }\end{array}$ & 12,13 \\
\hline Plakoglobin (2157del2TG) & Human & Autosomal recessive & $\begin{array}{l}\text { ARVC (arrhythmia, SCD, fibrofatty replacement } \\
\text { of cardiac myocytes, heart failure), woolly hair, } \\
\text { palmoplantar keratoderma (Naxos disease) }\end{array}$ & 51,78 \\
\hline $\begin{array}{l}\text { Vinculin/metavinculin } \\
\text { (Arg975Trp; Leu954del; Ala934Val) }\end{array}$ & Human & Autosomal dominant & $\begin{array}{l}\text { Dilated and hypertrophic cardiomyopathy, } \\
\text { progressive heart failure }\end{array}$ & $63,64,79$ \\
\hline $\begin{array}{l}\text { Vinculin/metavinculin } \\
\text { (Arg975Trp; Leu954del; Ala934Val) }\end{array}$ & Mouse & $\begin{array}{l}\text { Heterozygous } \\
\text { knockout mice }\end{array}$ & $\begin{array}{l}\text { Increased mortality and cardiac dysfunction } \\
\text { following acute hemodynamic stress imposed } \\
\text { by transverse aortic constriction }\end{array}$ & 62 \\
\hline
\end{tabular}

\section{Defect in desmosome}

Plakoglobin (2157del2TG)

Human Autosomal recessive

ARVC (arrhythmia, SCD, fibrofatty replacement of cardiac myocytes, heart failure), woolly hair, palmoplantar keratoderma (Naxos disease)

\begin{tabular}{|c|c|c|c|c|}
\hline Desmoplakin (Ser229Arg) & Human & Autosomal dominant & ARVC, no skin/hair phenotype & 56 \\
\hline Desmoplakin (2034insA) & Human & Autosomal dominant & Left-sided ARVC, no overt cutaneous disease & 55 \\
\hline Desmoplakin (7901del1G) & Human & Autosomal recessive & $\begin{array}{l}\text { Carvajal syndrome (left ventricular cardiomyopathy } \\
\text { with woolly hair and keratoderma) }\end{array}$ & 53 \\
\hline Desmoplakin (Gly2375Arg) & Human & Autosomal recessive & ARVC, woolly hair, no palmoplantar keratoderma & 57 \\
\hline Plakophilin-2 & Human & Autosomal recessive & ARVC & 58 \\
\hline \multicolumn{5}{|l|}{ efect in gap junctions } \\
\hline Connexin40 & Mouse & Germline deletion & AV block, inducible atrial tachyarrhythmia & 25,26 \\
\hline Connexin40 $(-44 \mathrm{G} \rightarrow \mathrm{A} ;+71 \mathrm{~A} \rightarrow \mathrm{G})$ & Human & Autosomal recessive & $\begin{array}{l}\text { Atrial standstill. Co-inherited with cardiac } \\
\text { sodium channel gene (SCN5A) Asp1275 } \\
\text { Asn mutation }\end{array}$ & 27 \\
\hline Connexin43 & Mouse & Cardiac-specific loss & $\begin{array}{l}\text { Spontaneous ventricular tachycardia, slow } \\
\text { conduction velocity, SCD }\end{array}$ & $28-30,80$ \\
\hline Connexin43 (Gly60Ser) & Mouse & Autosomal dominant & $\begin{array}{l}\text { Oculodentodigital dysplasia (syndactyly, } \\
\text { enamel hypoplasia, craniofacial anomalies and } \\
\text { cardiac dysfunction). Mild first degree AV block, } \\
\text { irregular sinus with AV dissociation and junctional } \\
\text { escape, bradycardia }\end{array}$ & 81 \\
\hline
\end{tabular}

ARVC, arrhythmogenic right ventricular cardiomyopathy; AV, atrioventricular; SCD, sudden cardiac death 
reentrant circuits. Cellular uncoupling, as a result of the loss of $\mathrm{Cx} 43$ gap junction channels, can unmask ectopic foci or trigger arrhythmias by enhancing the generation of early after-depolarizations, which then likely initiate arrhythmias due to functional reentry. ${ }^{28,31,32}$

\section{The Role of $\mathbf{N}$-cadherin in Stabilizing Gap Junctions in the Heart}

Cardiac myocytes are electrically coupled by exceptionally large gap junctions, ${ }^{33}$ which have presumably evolved to ensure that adequate electrical conduction is always maintained within the myocardium. Gap junctions in the heart are invariably located in close proximity to points of cell-cell adhesion within intercalated discs, which is also likely an evolutionary adaptation that acts to protect the gap junction from mechanical stress. Adherens junctions stabilize the plasma membrane of adjacent cardiomyocytes, which then helps to form an environment that is favorable for the formation and maintenance of large arrays of gap junctions. Several studies suggest that the principal adhesion molecule in the heart, $\mathrm{N}$-cadherin, plays an important role in the formation and/or function of gap junctions. Intracellular injection of antibodies directed against $\mathrm{N}$-cadherin inhibits dye transfer between Novikoff hepatoma cell pairs and the assembly of gap junctions. ${ }^{34}$ In addition, expression of a mutant $\mathrm{N}$-cadherin (which functions in a dominant negative fashion to suppress native $\mathrm{N}$-cadherin function) in adult rat cardiomyocytes resulted in disruption of cell-cell contacts and disassembly of gap junctions in these cells. ${ }^{35}$ Furthermore in our studies, cell surface expression of $\mathrm{Cx} 43$ is restored in $\mathrm{N}$-cadherin-null embryonic cardiomyocytes after introduction of a cadherin transgene. ${ }^{36}$ Another study showed that immunohistochemical analysis of dissociated adult rat ventricular myocytes reveals that the expected levels of $\mathrm{N}$-cadherin, $\beta$-catenin and plakoglobin are present with only a small amount of connexin at early stages of culture (days 3 to 4). Gap junctions became evident only once complete adherens junctions had formed and in all cases the new gap junctions were immediately adjacent to the adherens junctions (culture days 6 to 12). ${ }^{35,37-39}$ Pulsatile stretch in neonatal rat ventricular myocytes markedly upregulated the expression of proteins that form electrical and mechanical junctions, as well as increasing propagation velocity. ${ }^{40}$ Interestingly, the forced expression of $\alpha$-catenin in a $\alpha$-catenin-deficient prostate cancer cell line has been reported to rescue $\mathrm{Cx} 43$ trafficking to the cell surface. ${ }^{41}$ Further studies in NIH3T3 cells have shown that $\mathrm{Cx} 43$ cell surface trafficking and gap junction formation are dependent on the co-assembly of $\mathrm{Cx} 43$ in a $\mathrm{N}$-cadherin-containing multi-protein complex. ${ }^{42}$ Taken together, these findings suggest that N-cadherin not only plays a critical role in regulation of cell-cell adhesion, but also connexin assembly, trafficking and functional gap junction cellular coupling.

\section{Cardiac-specific Loss of $\mathbf{N}$-cadherin Leads to Alteration in Connexins with Arrhythmogenesis} The propensity for cardiac arrhythmogenesis is determined by

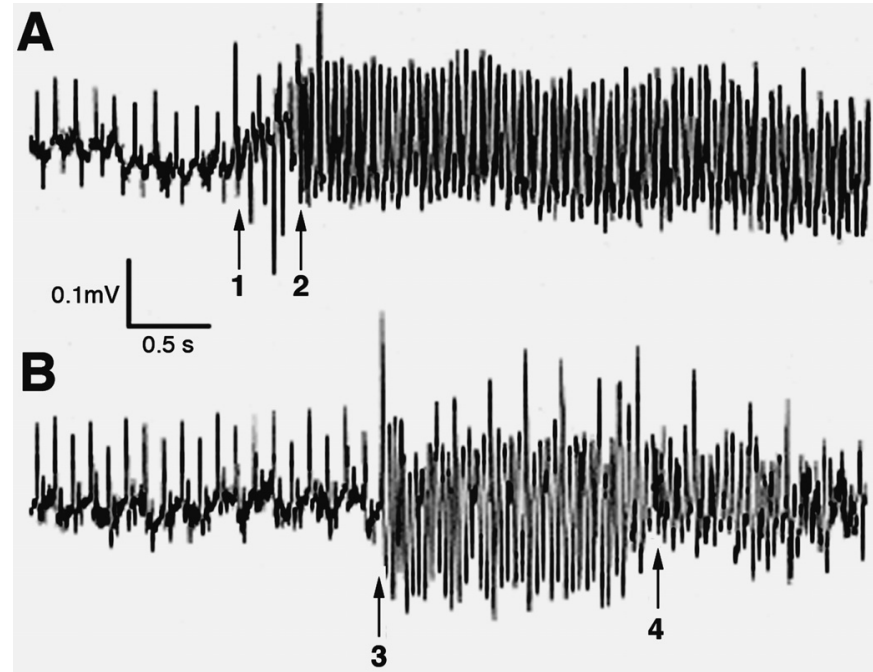

Figure 3. Spontaneous ventricular arrhythmias recorded from $\mathrm{N}$-cadherin CKO mice that died suddenly. Continuous electrocardiographic recordings from a miniaturized transmitter implanted in awake, freely mobile animals. (A) The left-hand side of the panel initially shows normal sinus activity with the onset of several premature ventricular beats (arrow 1) which then suddenly develops into ventricular tachycardia (arrow 2). (B) The left-hand side of the panel initially shows normal sinus activity with the sudden onset of ventricular tachycardia (arrow 3) which then quickly degenerates into ventricular fibrillation (arrow 4). Reprinted with permission from Kostetskii et al. Induced deletion of the $\mathrm{N}$-cadherin gene in the heart leads to dissolution of the intercalated disc structure. Circ Res 2005;96:346-354. Copyright 2005 Lippincott Williams \& Wilkins. All rights reserved.

a complex interplay between multi-factorial modifiers, such as external environmental factors, neurohormonal modulation, the genetic background/presence of disease causing mutations, and presence or absence of structural heart disease. ${ }^{43}$ For arrhythmogenesis to occur, both a suitable substrate (the disposing circumstances that allow perpetuation of the arrhythmia to occur) and a trigger (the event that initiates the arrhythmia within the substrate) need to be present simultaneously. ${ }^{44}$ The mechanism by which depleting $\mathrm{N}$-cadherin in the heart creates a substrate for ventricular arrhythmogenesis and SCD is probably also multi-factorial, but appears to be related to a loss of functional gap junctions with subsequent slowing in conduction velocity and an increase in tissue anisotropy. ${ }^{13}$

We have shown that loss of $\mathrm{N}$-cadherin in the heart alters connexin expression with loss of gap junctions from the cardiac intercalated disks that is associated with both spontaneous and inducible cardiac arrhythmias. ${ }^{12,13}$ We were able to document by telemetry electrocardiographic analysis that SCD in N-cad CKO mice was the result of spontaneous ventricular fibrillation in the absence of any clinical signs of heart failure (figure 3). Depletion of N-cadherin in the intercalated disc resulted in a significant decrease in both Cx43 (figure 4) and $\mathrm{Cx} 40$ in ventricular and atrial myocardium, respectively. Microscopic cellular heterogeneity of $\mathrm{Cx} 43$ expression in the absence of $\mathrm{N}$-cadherin was shown 


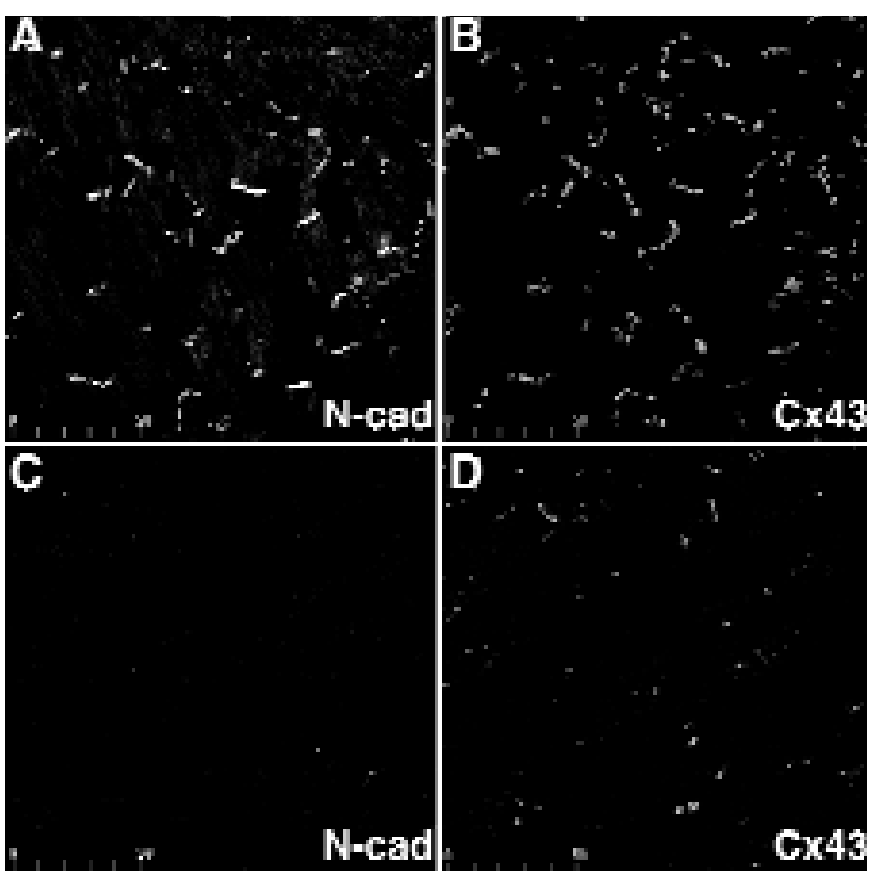

Figure 4. Expression of $\mathrm{Cx} 43$ in $\mathrm{N}$-cadherin $\mathrm{CKO}$ hearts. Hearts from wild-type (A, B) and N-cadherin CKO (C, D) animals 7 weeks post-tamoxifen were co-immunostained for $\mathrm{N}$-cadherin $(\mathrm{A}, \mathrm{C})$ and $\mathrm{C} \times 43(\mathrm{~B}, \mathrm{D})$ in the ventricle. $\mathrm{N}$-cadherin was lost from the intercalated disc in the CKO heart while Cx43 (D) was significantly decreased in the ventricular myocardium. Bar, $50 \mu \mathrm{m}$. Reprinted with permission from Li et al. Cardiac-specific loss of $\mathrm{N}$-cadherin leads to alteration in connexins with conduction slowing and arrhythmogenesis. Circ Res 2005;97:474-481. Copyright 2005 Lippincott Williams \& Wilkins. All rights reserved.

by reduced aggregate number, size, intensity and percent area occupied by $\mathrm{Cx} 43$ immunofluorescence signal in N-cad CKO mice compared to the control mice. ${ }^{13}$ The loss and heterogeneous redistribution of $\mathrm{Cx} 43$ in $\mathrm{N}$-cad $\mathrm{CKO}$ mice was associated with an approximately 50\% reduction in epicardial conduction velocity as well. This is of particular relevance since heterogeneous loss of $\mathrm{Cx} 43$ has been directly correlated with slowed epicardial conduction and an increased propensity for arrhythmogenesis in $\mathrm{Cx} 43 \mathrm{CKO}$ mice. ${ }^{28}$

Many connexins, including those expressed in the heart, have been found to turnover quite rapidly. ${ }^{45}$ The principal connexin expressed in the working ventricular myocardium, $\mathrm{Cx} 43$, is surprisingly short-lived (half-life $=1.3$ hours) in the intact adult heart. ${ }^{46} \mathrm{Cx} 43$ is phosphorylated when it forms an active gap junctional complex or channel at the cell surface 47 and it exists in a dephosphorylated state during trafficking/endocytosis within the cytoplasm. Enhanced degradation and turnover of connexins could reduce cell-cell coupling, slow conduction and promote reentrant arrhythmias. ${ }^{45}$ By using specific antibodies directed against one isoform of dephosphorylated $\mathrm{Cx} 43$ and total $\mathrm{Cx} 43,48$ as well as an antibody directed against $\mathrm{N}$-cadherin, we were able to quantify the expression of $\mathrm{Cx} 43$ following the depletion of $\mathrm{N}$-cadherin in the mouse heart over time by immunoblotting.
In this regard, we found that $\mathrm{N}$-cadherin was significantly decreased by day 6 post-induction, reaching $20 \%$ of endogenous levels by day 25, while Cx43 expression was significantly decreased by day 15 and reaching $40 \%$ of endogenous levels by day 41. Interestingly, a significant increase (2.5 fold) in the dephosphorylated species was observed at day 6 consistent with increased turnover of the protein immediately following loss of $\mathrm{N}$-cadherin. ${ }^{13}$ This result suggested that although $\mathrm{Cx} 43$ in $\mathrm{N}$-cad $\mathrm{CKO}$ heart is only reduced to about $40 \%$ of wild-type protein levels, the remaining $\mathrm{Cx} 43$ cannot be assembled into functional gap junctions at the intercalated disc in the absence of $\mathrm{N}$-cadherin. Therefore, we interpreted these findings to suggest that it was the loss of functional gap junctions at the cell surface that contributes to electrical cellular uncoupling and the creation of a heterogeneous substrate in N-cad CKO hearts to support arrhythmogenesis.

A similar situation may be found during situations which induce acute myocardial ischemia where changes in electrical coupling have been correlated with a marked reduction in the amount of phosphorylated $\mathrm{Cx} 43$ (which normally comprises approximately $85 \%$ of the total $\mathrm{Cx} 43$ content) and accumulation of dephosphorylated $\mathrm{Cx} 43$ within the cells, suggesting a translocation of $\mathrm{Cx} 43$ from functional gap junctions at the cell surface into the cytoplasmic, intracellular pool. ${ }^{49}$ Alterations in connexins have also been seen in nonischemic, dilated cardiomyopathy, where there appears to be an increase in dephosphorylated $\mathrm{Cx} 43$ with an increased distribution of $\mathrm{Cx} 43$ toward the lateral edges of the myocytes that results in gap junction dysfunction with conduction velocity slowing and arrhythmias. ${ }^{50}$ These observations provide further evidence implicating changes in phosphorylation and distribution of cardiac connexins as a major contributor to arrhythmogenesis.

As a consequence of tissue anisotropy, conduction velocity and the safety margin for conduction differ in longitudinal and transversal directions relative to the myocardial fiber orientation and blockade of conduction in either the transverse or longitudinal fiber direction might have differential effects upon arrhythmogenesis. ${ }^{44}$ In the normal heart there is usually greater cell-cell coupling and electrical conductance in a direction parallel to the long axis of the cardiac fiber (longitudinal) compared to the perpendicular (transverse) direction along the short axis of the fiber. These different conductive properties of the heart depend upon the orientation of the fibers and produce conduction anisotropy where action potentials propagate faster in the longitudinal direction compared to the transverse direction. Cardiac-specific deletion of $\mathrm{N}$-cadherin in mice results in an increase in the anisotropy ratio (AR), which is longitudinal conduction velocity/transverse conduction velocity, where transverse conduction is more greatly reduced than longitudinal conduction with an increase in the AR. Most likely, increased $\mathrm{AR}$ in the $\mathrm{N}$-cad $\mathrm{CKO}$ animals contributes to increased arrhythmogenesis by further promoting unidirectional block 
and slow conduction, on top of that induced by heterogeneous cellular uncoupling, similar to the results described in $\mathrm{Cx} 43$ CKO mice. ${ }^{28,29}$ Analogous to the finding that a reduction of Cx43 in the ventricular myocardium increases the propensity for ventricular tachyarrhythmias in N-cad CKO mice, these animals also have an increased propensity for induced atrial arrhythmias with a parallel, heterogeneous reduction of $\mathrm{Cx} 40$ and $\mathrm{Cx} 43$ within the atrial myocardium. The mechanism underlying the propensity for induced atrial arrhythmogenesis in this model is likely similar to that for the ventricular arrhythmias and related to the loss of the corresponding major connexin protein from the respective cardiac chamber. ${ }^{13}$

\section{Protein Interactions at the Intercellular Junction and Cardiac Arrhythmogenesis}

The importance of maintaining cell junction integrity was recently highlighted by the findings that mutations in the genes encoding plakoglobin and desmoplakin have been linked to an inheritable disorder known as arrhythmogenic right ventricular cardiomyopathy (ARVC) (table 1). Patients with ARVC are characterized by fibrofatty replacement of the right ventricular myocardium with a propensity for sustained ventricular tachycardia and SCD. It is estimated that over 1 million individuals worldwide are afflicted by ARVC, therefore ARVC is a relatively uncommon clinical disease. However, the fact that disease causing loci have been linked to mutations in several components of the cell adhesion complex in ARVC, understanding the link between cell adhesion complex dysfunction and arrhythmogenesis in ARVC has broader implications for understanding arrhythmogenesis in the more common diseases associated with cardiomyopathy. Plakoglobin, also known as $\gamma$-catenin, is a component of both adherens junctions and desmosomes in cardiac myocytes where it functions as an intracellular linker protein responsible for connecting adhesion molecules in cell-cell junctions to components of the cytoskeleton. ${ }^{39}$ Naxos disease, which is caused by a recessive mutation in plakoglobin, is associated with a high incidence of cardiac arrhythmias and SCD. Afflicted individuals usually present with dermatological abnormalities, including nonepidermolytic palmoplantar keratoderma and wooly hair. The disease causing mutation in Naxos disease is a deletion of nucleotides 2157 and 2158 in plakoglobin, which introduces a premature termination of translation and truncates the carboxyl terminus of the plakoglobin protein by 56 amino acids. It was recently demonstrated that $\mathrm{Cx} 43$ levels are significantly decreased in the hearts of Naxos patients, including a young patient who did not exhibit clinical or pathological features of structural heart disease. ${ }^{51}$

Another familial cardiocutaneous syndrome, Carvajal syndrome, was first described in 1998 by Dr. Luis Carvajal-Huerta. ${ }^{52}$ Carvajal syndrome is caused by a recessive mutation in the gene encoding desmoplakin and, like plakoglobin, desmoplakin is an intracellular protein that links desmosomal cadherins to the cytoskeleton. ${ }^{39}$ The disease causing mutation that has been identified in desmoplakin consists of a single nucleotide deletion (7901del1G) leading to a premature stop codon and a truncation of the carboxyl tail of the protein. ${ }^{53}$ Similar to Naxos disease, a recent pathological analysis of hearts from patients with Carvajal syndrome reported diminished expression of $\mathrm{Cx} 43$, in addition to loss of plakoglobin, at the intercalated disc. 54 Interestingly, two dominant forms of ARVC without cutaneous abnormalities have recently been attributed to mutations (Ser299Arg and 2034insA) in desmoplakin. 55,56 The Ser299Arg mutation (a point mutation) affects a putative phosphorylation site in the amino terminal domain of desmoplakin, which is thought to contribute to its interaction with plakoglobin. ${ }^{56}$ The 2034insA mutation (a single adenine insertion) causes a frameshift and introduction of a premature stop codon with truncation of the carboxy terminus, which is postulated to disrupt intermediate filament binding and may account for the predominant left-sided ARVC phenotype. An additional homozygous missense mutation in desmoplakin that has been linked to ARVC was reported in 2003. ${ }^{57}$ This mutation is single nucleotide substitution leading to a Gly2375Arg substitution in the carboxyl terminus of the protein, which is postulated to interact and bind to intermediate filaments. Therefore, evidence supports the postulation that mutations affecting proteins within the junctional complexes linked to ARVC most likely interfere with the linkage between these intercellular adhesion molecules, cytoskeleton and connexins leading to increased arrhythmogenesis in these patients.

Recently, mutations in the desmosomal protein plakophilin-2 have also been linked to ARVC. ${ }^{58}$ Mutations in the plakophilin-2 gene appear to be the most common ones associated with ARVC and are distributed throughout the gene and which include insertion-deletion, nonsense, missense and splice site mutations. ${ }^{58}$ The plakophilins are located in the outer dense plaque of the desmosome and link desmosomal cadherins with desmoplakin and the intermediate filament system. ${ }^{59}$ The lack of plakophilin-2, or incorporation of mutant plakophilin-2, into cardiac desmosomes may impair cell-cell contact and disrupt adjacent cardiomyocytes, particularly in response to mechanical stress. The development of myocardial fibrofatty degeneration in ARVC also contributes fixed regions of scar, with intrinsic variations in conduction properties that contribute to reentrant arrhythmias; these regions of altered conduction may be the result of impaired myocyte coupling due to abnormal junctional protein interactions. ${ }^{58}$ Therefore, it appears that defective linkage between desmosomes and the intermediate filaments (e.g., desmin) may have an additional effect upon the formation and maintenance of electrical junctions in the heart which, in turn, could contribute to conduction abnormalities and promote arrhythmogenesis.

\section{Transient Triggers or Modifiers Promote and Enhance Arrhythmias}

The spontaneous development of a lethal cardiac arrhythmia may be regarded as a stochastic event that arises from 
complex interactions between relatively fixed anatomic and functional substrates and transient triggering events. ${ }^{60}$ The triggering event could be induced by events such as acute ischemia, changes in neurohormonal activation, electrolyte abnormalities or other transient stresses which increase the risk of spontaneous lethal arrhythmias. In the case of ischemia-induced ventricular fibrillation, the triggers arise most often from timely administrated or spontaneous premature ventricular complexes that can be reentrant or non-reentrant in origin. ${ }^{44}$ Coronel et $\mathrm{al}^{61}$ found that the number of premature ventricular complexes were larger in working hearts than in isolated nonworking hearts. The triggers are initiated at the interface between the ischemic and the viable tissue and premature beats occur preferentially following potential contractions in the viable myocardium. In fact, decreased expression of vinculin/metavinculin in heterozygous vinculin mice has been linked to abnormal myocyte structure and stress-induced cardiomyopathy. ${ }^{62}$ Vinculin and its cardiac/smooth muscle-specific isoform metavinculin are protein components of intercalated discs, structures that anchor thin filaments and transmit contractile force between cardiac myocytes. Recently, three heterozygous metavinculin mutations were found in patients with dilated cardiomyopathy 63,64 and hypertrophic cardiomyopathy. ${ }^{64}$

In the absence of secondary stimuli, Cx43 heterozygous-null mice, which express only half the normal amount $\mathrm{Cx} 43$ in their hearts, do not develop spontaneous ventricular arrhythmias. These animals have normal longevity and exhibit only a subtle phenotype characterized by modest slowing of ventricular conduction velocity without apparent abnormalities in cardiac structure or function. 65 However, when acute ischemic injury is superimposed on the modest coupling defect produced by $\mathrm{Cx} 43$ deficiency, there is a marked increase in the incidence, frequency and duration of ventricular tachyarrhythmias. ${ }^{66}$ These data suggest that moderate diminutions of $\mathrm{Cx} 43$ expression or a modest coupling defect may be insufficient to create a highly arrhythmogenic substrate, but it may promote and enhance arrhythmias in response to acute ischemia or other secondary insults. It has been reported that $\mathrm{Cx} 43$ may be down-regulated by $25 \%$ to $50 \%$ in patients with chronic ventricular dysfunction and this may partially explain why such patients are at higher risk for suffering SCD. ${ }^{18,67}$ Thus, future studies in genetically engineered animal models are likely to be particularly informative in defining the role of specific gene products which contribute to the development of both arrhythmogenic triggers and substrates of which the structural linking proteins appear to be intimately involved.

Similar to $\mathrm{Cx} 43-/+$ animals, studies in our heterozygous $\mathrm{N}$-cadherin knockout mice revealed no significant differences in electrocardiogram or intracardiac electrophysiological parameters compared to the control mice. However, heterozygous N-cadherin animals did exhibit increased vulnerability to inducible tachycardia (J.L., V.V.P. and G.L.R., unpublished data). Interestingly, there was a 2-fold increase in dephosphorylated $\mathrm{Cx} 43$ in heterozygous hearts accompanied by a modest decrease (approximately 10\%) in total $\mathrm{Cx} 43$ protein. This observation suggested that reduction of N-cadherin (e.g., haploinsufficiency) contributes to arrhythmogenesis and conduction disturbances by affecting gap junction structure and function. We will further examine how treadmill-induced stress enhances cardiac arrhythmia in the N-cadherin mutant mice and if it affects phosphorylation status of Cx43. Study of the heterozygous N-cadherin mice, which may serve as a model of arrhythmogenesis in patients who do not present with an overt cardiomyopathy, may provide insight into the mechanism of arrhythmogenesis in diseased myocardium.

\section{Future Direction}

Recognizing and understanding the contribution of the cardiac substrate to arrhythmogenesis is critical for the pathologic analysis of SCD, but this can only be accomplished by also understanding the complex, dynamic interactions between substrates and transient triggers. 68 So far, $\mathrm{N}$-cadherin mutations have only been studied in animal models, but these studies have provided evidence that cell adhesion molecules mediate both mechanical and electrical coupling between myocytes which when perturbed leads to an arrhythmogenic substrate. It appears that N-cadherin mediates these effects predominately through its regulation of cardiac gap junctions. Future human studies will be required to elucidate the role of $\mathrm{N}$-cadherin in arrhythmogenesis and mechanisms responsible for arrhythmogenic cardiomyopathy and sudden death. It will be interesting to determine which components of the cadherin/catenin complex are important contributors to cardiac arrhythmias in disease and how the adherens junction may arise as a novel target for therapy in the prevention of SCD.

Recently, a novel peptide, ZP123, has been reported to stimulate gap junction intercellular communication between cardiomyocytes $^{69-72}$ and human osteoblasts. ${ }^{73}$ ZP123 was shown to promote electrical coupling between ventricular myocytes and reduce the rate of inducible ventricular tachycardia during acute ischemia in dogs, suggesting an antiarrhythmic effect associated with the targeting of gap junctions. ${ }^{74,75}$ Interestingly, ZP123 was also reported to prevent conduction velocity slowing and heterogeneous repolarization and eliminate arrhythmogenic substrates. ${ }^{76}$ Most recently, ZP123 was reported to suppress dephosphorylation of serine 297 and serine 368 in gap junction protein, $\mathrm{Cx} 43$ and to significantly increase the time to ischemia-induced asystole. ${ }^{77}$ It will be interesting to determine whether ZP123 increases intercellular coupling to prevent induced ventricular tachycardia in $\mathrm{N}$-cadherin haploinsufficient mice.

\section{References}

1. Schaper J, Froede R, Hein S, Buck A, Hashizume H, Speiser B, Friedl A, Bleese N. Impairment of the myocardial ultrastructure and changes of the cytoskeleton in dilated cardiomyopathy. Circulation 1991;83:504-514. 
2. Kostin S, Klein G, Szalay Z, Hein S, Bauer EP, Schaper J. Structural correlate of atrial fibrillation in human patients. Cardiovasc Res 2002;54:361-379.

3. Tomaselli GF, Beuckelmann DJ, Calkins HG, Berger RD, Kessler PD, Lawrence JH, Kass D, Feldman AM, Marban E. Sudden cardiac death in heart failure. The role of abnormal repolarization. Circulation 1994;90:2534-2539.

4. Matsushita T, Oyamada M, Fujimoto K, Yasuda Y, Masuda S, Wada Y, Oka T, Takamatsu T. Remodeling of cell-cell and cell-extracellular matrix interactions at the border zone of rat myocardial infarcts. Circ Res 1999;85:1046-1055.

5. Wang X, Gerdes AM. Chronic pressure overload cardiac hypertrophy and failure in guinea pigs: III. Intercalated disc remodeling. J Mol Cell Cardiol 1999;31:333-343.

6. Volk T, Geiger B. A 135-kd membrane protein of intercellular adherens junctions. EMBO J 1984;3:2249-2260.

7. Goncharova EJ, Kam Z, Geiger B. The involvement of adherens junction components in myofibrillogenesis in cultured cardiac myocytes. Development 1992;114:173-183.

8. Gumbiner BM. Regulation of cadherin adhesive activity. J Cell Biol 2000;148:399-404.

9. Radice GL, Rayburn H, Matsunami H, Knudsen KA, Takeichi M, Hynes RO. Developmental defects in mouse embryos lacking N-cadherin. Dev Biol 1997;181:64-78.

10. Ferreira-Cornwell MC, Luo Y, Narula N, Lenox JM, Lieberman M, Radice GL. Remodeling the intercalated disc leads to cardiomyopathy in mice misexpressing cadherins in the heart. J Cell Sci 2002;115:1623-1634.

11. Kostetskii I, Moore R, Kemler R, Radice GL. Differential adhesion leads to segregation and exclusion of N-cadherin-deficient cells in chimeric embryos. Dev Biol 2001;234:72-79.

12. Kostetskii I, Li J, Xiong Y, Zhou R, Ferrari VA, Patel VV, Molkentin JD, Radice GL. Induced deletion of the N-cadherin gene in the heart leads to dissolution of the intercalated disc structure. Circ Res 2005;96:346-354.

13. Li J, Patel VV, Kostetskii I, Xiong Y, Chu AF, Jacobson JT, Yu C, Morley GE, Molkentin JD, Radice GL. Cardiac-specific loss of N-cadherin leads to alteration in connexins with conduction slowing and arrhythmogenesis. Circ Res 2005;97:474-481.

14. Honjo H, Boyett MR, Coppen SR, Takagishi Y, Opthof T, Severs NJ, Kodama I. Heterogeneous expression of connexins in rabbit sinoatrial node cells: correlation between connexin isotype and cell size. Cardiovasc Res 2002;53:89-96.

15. Kanter HL, Laing JG, Beyer EC, Green KG, Saffitz JE. Multiple connexins colocalize in canine ventricular myocyte gap junctions. Circ Res 1993;73:344-350.

16. Yeh HI, Rothery S, Dupont E, Coppen SR, Severs NJ. Individual gap junction plaques contain multiple connexins in arterial endothelium. Circ Res 1998;83:1248-1263.

17. Saffitz JE, Kleber AG. Effects of mechanical forces and mediators of hypertrophy on remodeling of gap junctions in the heart. Circ Res 2004;94:585-591.

18. Peters NS, Green CR, Poole-Wilson PA, Severs NJ. Reduced content of connexin43 gap junctions in ventricular myocardium from hypertrophied and ischemic human hearts. Circulation 1993;88:864-875.

19. Dupont E, Matsushita T, Kaba RA, Vozzi C, Coppen SR, Khan N, Kaprielian R, Yacoub MH, Severs NJ. Altered connexin expression in human congestive heart failure. J Mol Cell Cardiol 2001;33:359-371.

20. Smith JH, Green CR, Peters NS, Rothery S, Severs NJ. Altered patterns of gap junction distribution in ischemic heart disease. An immunohistochemical study of human myocardium using laser scanning confocal microscopy. Am J Pathol 1991;139:801-821.
21. Daleau P, Boudriau S, Michaud M, Jolicoeur C, Kingma JG Jr. Preconditioning in the absence or presence of sustained ischemia modulates myocardial $\mathrm{Cx} 43$ protein levels and gap junction distribution. Can J Physiol Pharmacol 2001;79:371-378.

22. Peters NS, Coromilas J, Severs NJ, Wit AL. Disturbed connexin43 gap junction distribution correlates with the location of reentrant circuits in the epicardial border zone of healing canine infarcts that cause ventricular tachycardia. Circulation 1997;95:988-996.

23. Sepp R, Severs NJ, Gourdie RG. Altered patterns of cardiac intercellular junction distribution in hypertrophic cardiomyopathy. Heart 1996;76:412-417.

24. Simon AM, Goodenough DA. Diverse functions of vertebrate gap junctions. Trends Cell Biol 1998;8:477-483.

25. Kirchhoff S, Nelles E, Hagendorff A, Kruger O, Traub O, Willecke K. Reduced cardiac conduction velocity and predisposition to arrhythmias in connexin40-deficient mice. Curr Biol 1998;8:299-302.

26. Hagendorff A, Schumacher B, Kirchhoff S, Luderitz B, Willecke K. Conduction disturbances and increased atrial vulnerability in Connexin40-deficient mice analyzed by transesophageal stimulation. Circulation 1999;99:1508-1515.

27. Groenewegen WA, Firouzi M, Bezzina CR, Vliex S, van Langen IM, Sandkuijl L, Smits JP, Hulsbeek M, Rook MB, Jongsma HJ, Wilde AA. A cardiac sodium channel mutation cosegregates with a rare connexin 40 genotype in familial atrial standstill. Circ Res 2003;92:14-22.

28. Gutstein DE, Morley GE, Tamaddon H, Vaidya D, Schneider MD, Chen J, Chien KR, Stuhlmann H, Fishman GI. Conduction slowing and sudden arrhythmic death in mice with cardiac-restricted inactivation of connexin43. Circ Res 2001;88:333-339.

29. van Rijen HV, Eckardt D, Degen J, Theis M, Ott T, Willecke K, Jongsma HJ, Opthof T, de Bakker JM. Slow conduction and enhanced anisotropy increase the propensity for ventricular tachyarrhythmias in adult mice with induced deletion of connexin43. Circulation 2004;109:1048-1055.

30. Eckardt D, Theis M, Degen J, Ott T, van Rijen HV, Kirchhoff S, Kim JS, de Bakker JM, Willecke K. Functional role of connexin43 gap junction channels in adult mouse heart assessed by inducible gene deletion. J Mol Cell Cardiol 2004;36:101-110.

31. Gutstein DE, Danik SB, Lewitton S, France D, Liu F, Chen FL, Zhang J, Ghodsi N, Morley GE, Fishman GI. Focal gap junction uncoupling and spontaneous ventricular ectopy. Am J Physiol Heart Circ Physiol 2005;289:H1091-H1098.

32. Wilders R, Wagner MB, Golod DA, Kumar R, Wang YG, Goolsby WN, Joyner RW, Jongsma HJ. Effects of anisotropy on the development of cardiac arrhythmias associated with focal activity. Pflugers Arch 2000;441:301-312.

33. Hoyt RH, Cohen ML, Saffitz JE. Distribution and three-dimensional structure of intercellular junctions in canine myocardium. Circ Res 1989;64:563-574.

34. Meyer RA, Laird DW, Revel JP, Johnson RG. Inhibition of gap junction and adherens junction assembly by connexin and A-CAM antibodies. J Cell Biol 1992;119:179-189.

35. Hertig CM, Eppenberger-Eberhardt M, Koch S, Eppenberger HM. N-cadherin in adult rat cardiomyocytes in culture. I. Functional role of N-cadherin and impairment of cell-cell contact by a truncated N-cadherin mutant. J Cell Sci 1996;109:1-10.

36. Luo Y, Radice GL. Cadherin-mediated adhesion is essential for myofibril continuity across the plasma membrane but not for assembly of the contractile apparatus. J Cell Sci 2003;116:1471-1479.

37. Kostin S, Hein S, Bauer EP, Schaper J. Spatiotemporal development and distribution of intercellular junctions in adult rat cardiomyocytes in culture. Circ Res 1999;85:154-167. 
38. Hertig CM, Butz S, Koch S, Eppenberger-Eberhardt M, Kemler R, Eppenberger HM. N-cadherin in adult rat cardiomyocytes in culture. II. Spatio-temporal appearance of proteins involved in cell-cell contact and communication. Formation of two distinct N-cadherin/catenin complexes. J Cell Sci 1996;109:11-20.

39. Zuppinger C, Schaub MC, Eppenberger HM. Dynamics of early contact formation in cultured adult rat cardiomyocytes studied by $\mathrm{N}$-cadherin fused to green fluorescent protein. $\mathrm{J}$ Mol Cell Cardiol 2000;32:539-555.

40. Zhuang J, Yamada KA, Saffitz JE, Kleber AG. Pulsatile stretch remodels cell-to-cell communication in cultured myocytes. Circ Res 2000;87:316-322.

41. Govindarajan R, Zhao S, Song XH, Guo RJ, Wheelock M, Johnson KR, Mehta PP. Impaired trafficking of connexins in androgen-independent human prostate cancer cell lines and its mitigation by alpha-catenin. J Biol Chem 2002;277:50087-50097.

42. Wei CJ, Francis R, Xu X, Lo CW. Connexin43 associated with an $\mathrm{N}$-cadherin-containing multiprotein complex is required for gap junction formation in NIH3T3 cells. J Biol Chem 2005;280:19925-19936.

43. Cheng CF, Kuo HC, Chien KR. Genetic modifiers of cardiac arrhythmias. Trends Mol Med 2003;9:59-66.

44. De Groot JR, Coronel R. Acute ischemia-induced gap junctional uncoupling and arrhythmogenesis. Cardiovasc Res 2004;62:323-334.

45. Saffitz JE, Laing JG, Yamada KA. Connexin expression and turnover: implications for cardiac excitability. Circ Res 2000;86:723-728.

46. Beardslee MA, Laing JG, Beyer EC, Saffitz JE. Rapid turnover of connexin43 in the adult rat heart. Circ Res 1998;83:629-635.

47. Musil LS, Goodenough DA. Biochemical analysis of connexin43 intracellular transport, phosphorylation, and assembly into gap junctional plaques. J Cell Biol 1991;115:1357-1374.

48. Nagy JI, Li WE, Roy C, Doble BW, Gilchrist JS, Kardami E, Hertzberg EL. Selective monoclonal antibody recognition and cellular localization of an unphosphorylated form of connexin43. Exp Cell Res 1997;236:127-136.

49. Beardslee MA, Lerner DL, Tadros PN, Laing JG, Beyer EC, Yamada KA, Kleber AG, Schuessler RB, Saffitz JE. Dephosphorylation and intracellular redistribution of ventricular connexin43 during electrical uncoupling induced by ischemia. Circ Res 2000;87:656-662.

50. Akar FG, Spragg DD, Tunin RS, Kass DA, Tomaselli GF. Mechanisms underlying conduction slowing and arrhythmogenesis in nonischemic dilated cardiomyopathy. Circ Res 2004;95:717-725.

51. Kaplan SR, Gard JJ, Protonotarios N, Tsatsopoulou A, Spiliopoulou C, Anastasakis A, Squarcioni CP, McKenna WJ, Thiene G, Basso C, Brousse N, Fontaine G, Saffitz JE. Remodeling of myocyte gap junctions in arrhythmogenic right ventricular cardiomyopathy due to a deletion in plakoglobin (Naxos disease). Heart Rhythm 2004;1:3-11.

52. Carvajal-Huerta L. Epidermolytic palmoplantar keratoderma with woolly hair and dilated cardiomyopathy. J Am Acad Dermatol 1998;39:418-421.

53. Norgett EE, Hatsell SJ, Carvajal-Huerta L, Cabezas JC, Common J, Purkis PE, Whittock N, Leigh IM, Stevens HP, Kelsell DP. Recessive mutation in desmoplakin disrupts desmoplakin-intermediate filament interactions and causes dilated cardiomyopathy, woolly hair and keratoderma. Hum Mol Genet 2000;9:2761-2766.

54. Kaplan SR, Gard JJ, Carvajal-Huerta L, Ruiz-Cabezas JC, Thiene G, Saffitz JE. Structural and molecular pathology of the heart in Carvajal syndrome. Cardiovasc Pathol 2004;13:26-32.
55. Norman M, Simpson M, Mogensen J, Shaw A, Hughes S, Syrris P, Sen-Chowdhry S, Rowland E, Crosby A, McKenna WJ. Novel mutation in desmoplakin causes arrhythmogenic left ventricular cardiomyopathy. Circulation 2005;112:636-642.

56. Rampazzo A, Nava A, Malacrida S, Beffagna G, Bauce B, Rossi V, Zimbello R, Simionati B, Basso C, Thiene G, Towbin JA, Danieli GA. Mutation in human desmoplakin domain binding to plakoglobin causes a dominant form of arrhythmogenic right ventricular cardiomyopathy. Am J Hum Genet 2002;71:1200-1206.

57. Alcalai R, Metzger S, Rosenheck S, Meiner V, Chajek-Shaul T. A recessive mutation in desmoplakin causes arrhythmogenic right ventricular dysplasia, skin disorder, and woolly hair. J Am Coll Cardiol 2003;42:319-327.

58. Gerull B, Heuser A, Wichter T, Paul M, Basson CT, McDermott DA, Lerman BB, Markowitz SM, Ellinor PT, MacRae CA, Peters S, Grossmann KS, Drenckhahn J, Michely B, Sasse-Klaassen S, Birchmeier W, Dietz R, Breithardt G, Schulze-Bahr E, Thierfelder L. Mutations in the desmosomal protein plakophilin-2 are common in arrhythmogenic right ventricular cardiomyopathy. Nat Genet 2004;36:1162-1164.

59. Mertens C, Kuhn C, Franke WW. Plakophilins 2a and 2b: constitutive proteins of dual location in the karyoplasm and the desmosomal plaque. J Cell Biol 1996;135:1009-1025.

60. Zipes DP, Wellens HJ. Sudden cardiac death. Circulation 1998;98:2334-2351.

61. Coronel R, Wilms-Schopman FJ, deGroot JR. Origin of ischemia-induced phase $1 \mathrm{~b}$ ventricular arrhythmias in pig hearts. J Am Coll Cardiol 2002;39:166-176.

62. Zemljic-Harpf AE, Ponrartana S, Avalos RT, Jordan MC, Roos KP, Dalton ND, Phan VQ, Adamson ED, Ross RS. Heterozygous inactivation of the vinculin gene predisposes to stress-induced cardiomyopathy. Am J Pathol 2004;165:1033-1044.

63. Olson TM, Illenberger S, Kishimoto NY, Huttelmaier S, Keating MT, Jockusch BM. Metavinculin mutations alter actin interaction in dilated cardiomyopathy. Circulation 2002;105:431-437.

64. Vasile VC, Will ML, Ommen SR, Edwards WD, Olson TM, Ackerman MJ. Identification of a metavinculin missense mutation, R975W, associated with both hypertrophic and dilated cardiomyopathy. Mol Genet Metab 2005 Oct 15; [Epub ahead of print].

65. Eloff BC, Lerner DL, Yamada KA, Schuessler RB, Saffitz JE, Rosenbaum DS. High resolution optical mapping reveals conduction slowing in connexin43 deficient mice. Cardiovasc Res 2001;51:681-690.

66. Lerner DL, Yamada KA, Schuessler RB, Saffitz JE. Accelerated onset and increased incidence of ventricular arrhythmias induced by ischemia in $\mathrm{Cx} 43$-deficient mice. Circulation 2000;101:547-552.

67. Kaprielian RR, Gunning M, Dupont E, Sheppard MN, Rothery SM, Underwood R, Pennell DJ, Fox K, Pepper J, Poole-Wilson PA, Severs NJ. Downregulation of immunodetectable connexin43 and decreased gap junction size in the pathogenesis of chronic hibernation in the human left ventricle. Circulation 1998;97:651-660.

68. Saffitz JE. The pathology of sudden cardiac death in patients with ischemic heart disease - arrhythmology for anatomic pathologists. Cardiovasc Pathol 2005;14:195-203.

69. Aonuma S, Kohama Y, Akai K, Komiyama Y, Nakajima S, Wakabayashi M, Makino T. Studies on heart. XIX. Isolation of an atrial peptide that improves the rhythmicity of cultured myocardial cell clusters. Chem Pharm Bull (Tokyo) 1980;28:3332-3339.

70. Muller A, Gottwald M, Tudyka T, Linke W, Klaus W, Dhein S. Increase in gap junction conductance by an antiarrhythmic peptide. Eur J Pharmacol 1997;327:65-72. 
71. Daleau P. Effects of antiarrhythmic agents on junctional resistance of guinea pig ventricular cell pairs. J Pharmacol Exp Ther 1998;284:1174-1179.

72. Dhein S, Manicone N, Muller A, Gerwin R, Ziskoven U, Irankhahi A, Minke C, Klaus W. A new synthetic antiarrhythmic peptide reduces dispersion of epicardial activation recovery interval and diminishes alterations of epicardial activation patterns induced by regional ischemia. A mapping study. Naunyn Schmiedebergs Arch Pharmacol 1994;350:174-184.

73. Jorgensen NR, Teilmann SC, Henriksen Z, Meier E, Hansen SS, Jensen JE, Sorensen OH, Petersen JS. The antiarrhythmic peptide analog rotigaptide (ZP123) stimulates gap junction intercellular communication in human osteoblasts and prevents decrease in femoral trabecular bone strength in ovariectomized rats. Endocrinology 2005;146:4745-4754.

74. Xing D, Kjolbye AL, Nielsen MS, Petersen JS, Harlow KW, Holstein-Rathlou NH, Martins JB. ZP123 increases gap junctional conductance and prevents reentrant ventricular tachycardia during myocardial ischemia in open chest dogs. J Cardiovasc Electrophysiol 2003; 14:510-520.

75. Kjolbye AL, Knudsen CB, Jepsen T, Larsen BD, Petersen JS. Pharmacological characterization of the new stable antiarrhythmic peptide analog Ac-D-Tyr-D-Pro-D-Hyp-Gly-D-Ala-Gly-NH2 (ZP123): in vivo and in vitro studies. J Pharmacol Exp Ther 2003;306:1191-1199.

76. Eloff BC, Gilat E, Wan X, Rosenbaum DS. Pharmacological modulation of cardiac gap junctions to enhance cardiac conduction: evidence supporting a novel target for antiarrhythmic therapy. Circulation 2003;108:3157-3163.

77. Axelsen LN, Mohammed S, Kjolbye AL, Nielsen MS, Holstein-Rathlou NH, Jensen ON, Andersen S, Hennan JK, Stahlhut M. Serine 297 and serine 306: Two new phosphorylation sites involved in the regulation of connexin43 during ischemia. Circulation (supplement) 2005;112:II-114, Abstract 635.

78. McKoy G, Protonotarios N, Crosby A, Tsatsopoulou A, Anastasakis A, Coonar A, Norman M, Baboonian C, Jeffery $\mathrm{S}, \mathrm{McKenna}$ WJ. Identification of a deletion in plakoglobin in arrhythmogenic right ventricular cardiomyopathy with palmoplantar keratoderma and woolly hair (Naxos disease). Lancet 2000;355:2119-2124.

79. Maeda M, Holder E, Lowes B, Valent S, Bies RD. Dilated cardiomyopathy associated with deficiency of the cytoskeletal protein metavinculin. Circulation 1997;95:17-20.

80. Danik SB, Liu F, Zhang J, Suk HJ, Morley GE, Fishman GI, Gutstein DE. Modulation of cardiac gap junction expression and arrhythmic susceptibility. Circ Res 2004;95:1035-1041.

81. Flenniken AM, Osborne LR, Anderson N, Ciliberti N, Fleming C, Gittens JE, Gong XQ, Kelsey LB, Lounsbury C, Moreno L, Nieman BJ, Peterson K, Qu D, Roscoe W, Shao Q, Tong D, Veitch GI, Voronina I, Vukobradovic I, Wood GA, Zhu Y, Zirngibl RA, Aubin JE, Bai D, Bruneau BG, Grynpas M, Henderson JE, Henkelman RM, McKerlie C, Sled JG, Stanford WL, Laird DW, Kidder GM, Adamson SL, Rossant J. A Gja1 missense mutation in a mouse model of oculodentodigital dysplasia. Development 2005;132:4375-4386.
Author Affiliations

Jifen Li, MD, PhD, Center for Research on Reproduction and Women's Health, University of Pennsylvania School of Medicine, Philadelphia, Pennsylvania

Vickas V. Patel, MD, PhD, Division of Cardiovascular Medicine, University of Pennsylvania School of Medicine, Philadelphia, Pennsylvania

Glenn L. Radice, PhD, Center for Research on Reproduction and Women's Health, University of Pennsylvania School of Medicine, Philadelphia, Pennsylvania 